\title{
خهو قالزون
}

\section{حرية تداول المعلومات والورثاثة}

في إطسار البـاب الثاني مـن الدستور

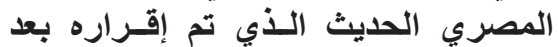
الاستفتاء عليه وموافقة أغلبية المصرين

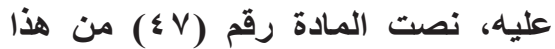

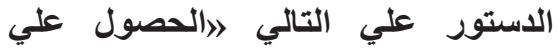

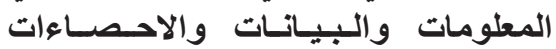
والوثائق، والإفصاح عنها، وتداولها، حق والت

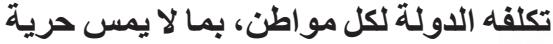

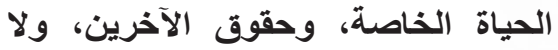
يتعارض مع الأم القومي. وينظم القانون قواعد إيـاع الوثائق العامة وحفظها، وطريقة الحصول علي اعلى المعلومات،

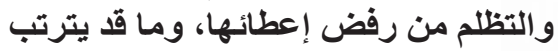
علي هذا الرفض من مساءلة التهاء. هذه المادة

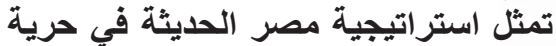
المعلومات وحقوق المواطنين في النفاذ

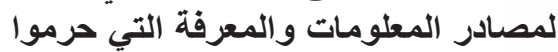

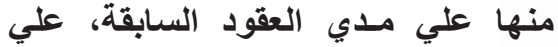
الرغم من أن الأمم المتحدة منذ إنشائها

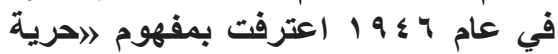

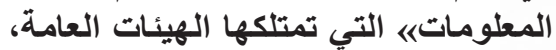
وفي خلال الدورة الأولي للجمعية لعمومية، التمات التهاتية

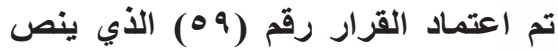

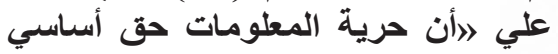
من حقوق الإنسان والنموذج الأساسي للحريات التي وهيت للإنسانهان والنوده

وعلي الرغم من بعض القوانين الأولية التي تضمن الحق بالنفاذ إلي المعلومات التمات التمات

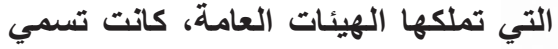
بالقوانين المتعلقة بحرية المعلومات، إلاتية

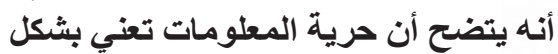

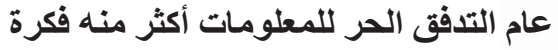
الحق بالنفاذ إلي المعلومات التي تمتلكها

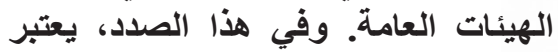

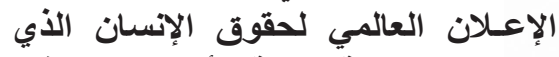
اعتمدته الجمعية العامة للأمم المتحدة في الأليان الأي
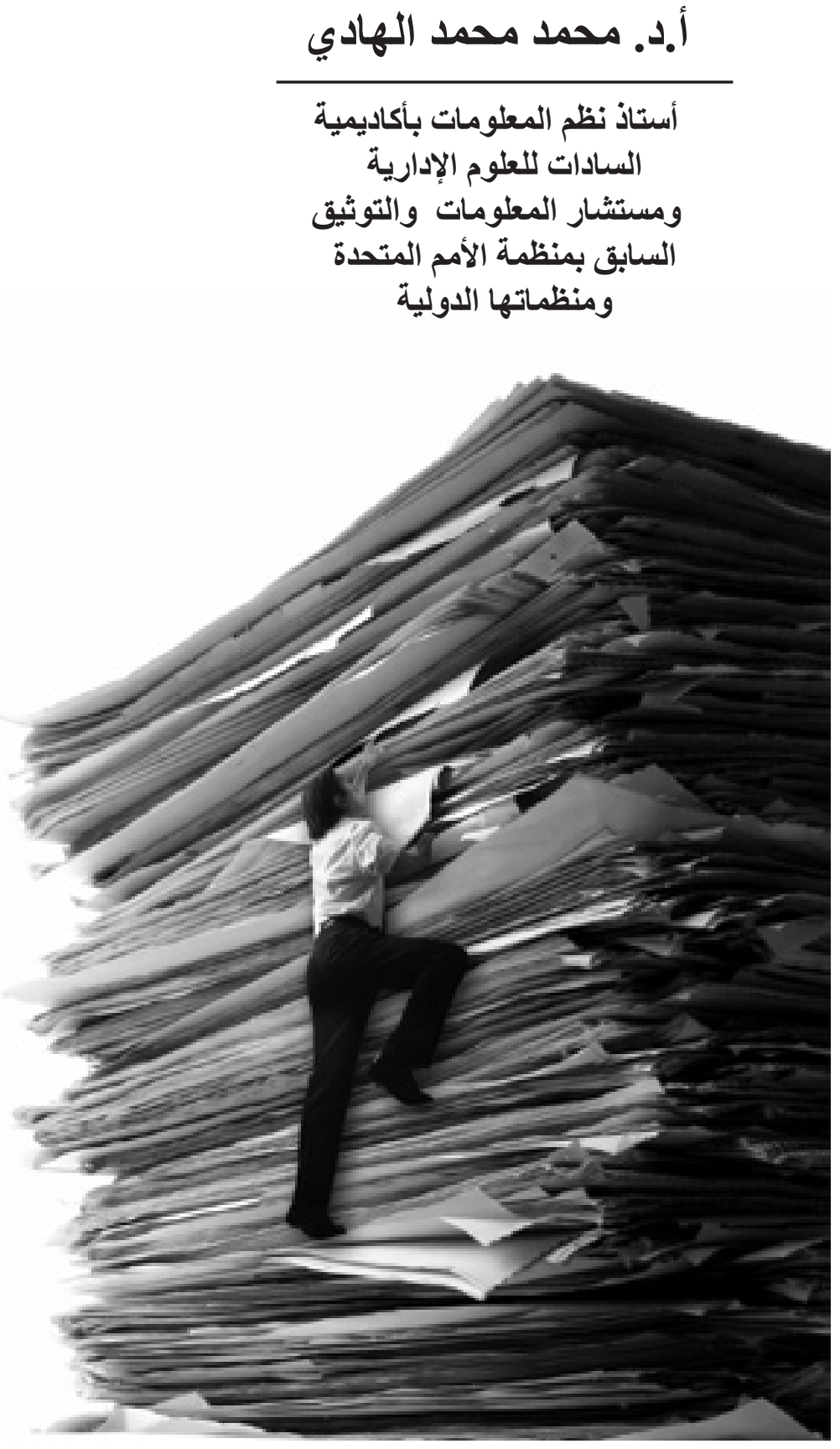


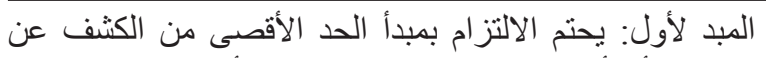

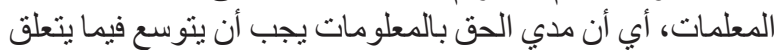

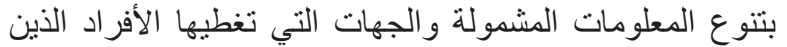
يطالبون بهذا الحق، حيث أن كل المعلومات تعتبر قابلة للنفاذ و لا لإل تخضع إلا لنظام محدود من الاستثناءات.

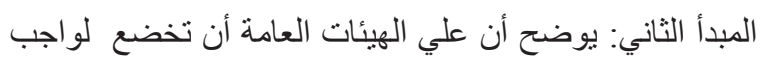

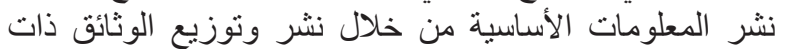

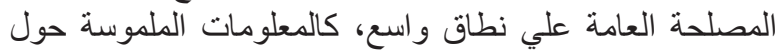
كيفية عملها ومضمون أب قرار أو سياسة تؤثر علي الناس.

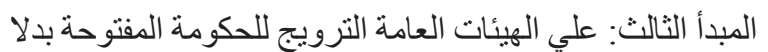

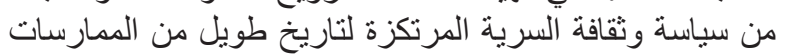

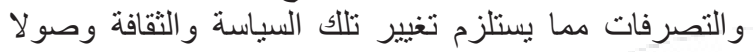

$$
\text { لحوكمة السلطة. }
$$

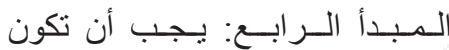

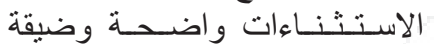

وخاضعة لاختبار ات صارمة واضنة

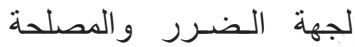

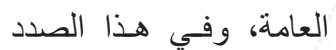

تسطـالب مسعايبـر الأمسم

المتحدة بأن تكون تلائلك الاهن

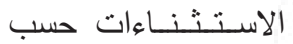

القانون ومحدودة بشكل

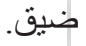

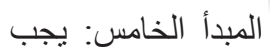

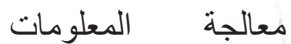

بطريقة سريعة ومر اجعة

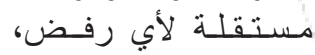

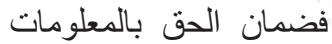

ليس كثنفا وقائيا للمعلومات بالمعات

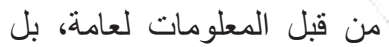

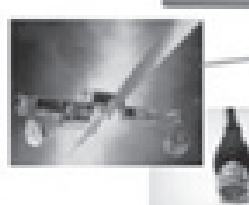

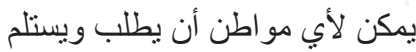

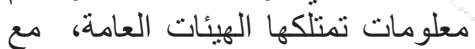

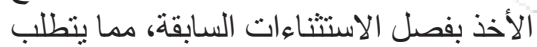

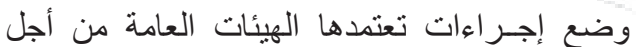

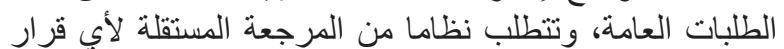

داخلي متخذ.

المبدأ السادس: لا يفترض بالأفر اد الامتتاع عن التقدم بطلب النفاذ

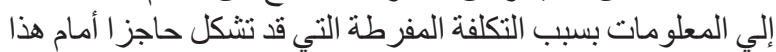
النفاذ مما قد يقوض دعائم هذا الحق.

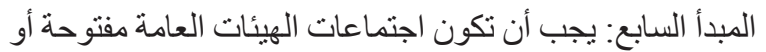
متاح جلساتها للجميع بدلا من الانغلاق.

المبدأ الثامن: يجب تعديل القو انين التي لا نتماشي مع مبدأ الحد بد بلدي

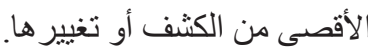

المبدأ التاسع: يجب حماية الأفراد الذين يبلغون عن المعلومات
عام 19 19 في البيان الرائد المرتبط بحقوق الإنسان علي

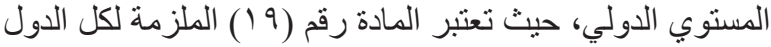

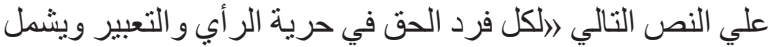

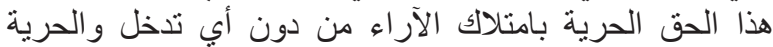

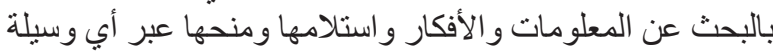

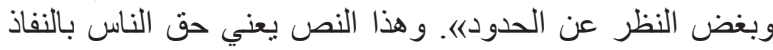

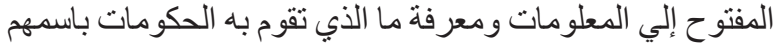
و هو حق من دونه تضعف الحقيقة وتبقي مشاركة الناس في الحكم مجز أة وناقصة.

وبل إن تقرير المقرر الخاص التابع للأمم المتحدة لحرية الر أي

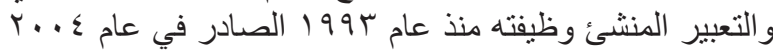

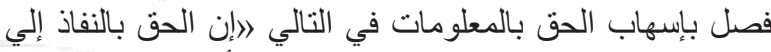

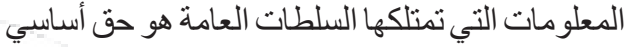
من حقوق الإنسان يجب أن بلقي التنفيذ علي هائ

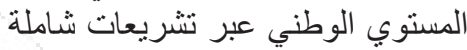
(علي سبيل المثال قوانين حرية تُبرية المعلومات) بالارتكاز إلي مبدأ

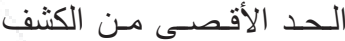

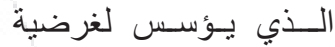
تقضي أن كل المعلومات لغونية

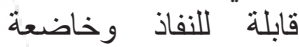
فقط لمجال ضيق من لإن

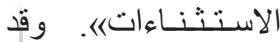
اعترفت أنظمة حقوف الأن الإنسان الإقليمية الثلاثة المرتبطة بمنظمة الدول

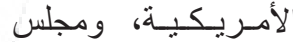

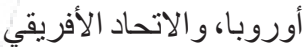

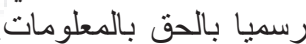

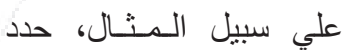
الاتحاد الأفريقي مبادئ حرية

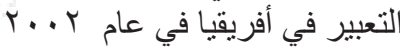

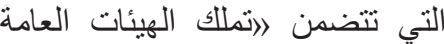
المعلومات ليس لنفسها بل تكون راعية العية لممتلكات العموم من الناس فيحق للجنميع النون راعية النفاذ للمعلومات التي لا تخضع إلا لقو اعد و اضحة يضعها القانونها. وفي هذا الصدد، اعتبر عدد من المحاكم الكبرى حول العالم

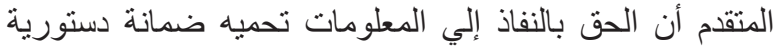

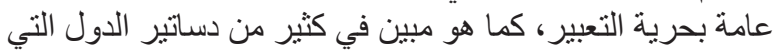

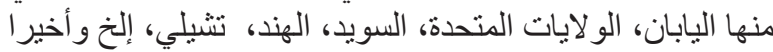

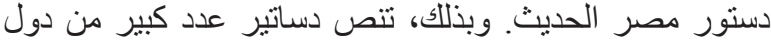

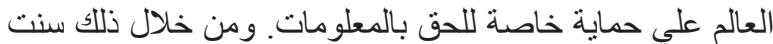
التشريعات و القوانين التي تطالب بحرية المعلومات والت والتي تفصل

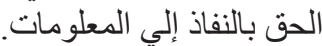

ومن المبادئ الأساسية التي تنص عليها قو انين وتشريعات حرية

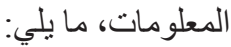


على أجهزة خاصة، أو أية أنثكال أخرى برى المفوض العام أنها تدخل في نطاق المعلومة وفقاه ألهذا القانون.

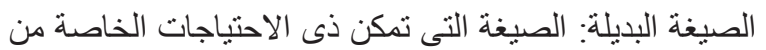

$$
\text { الاطلاع على المعلومة المطلوبة. }
$$

الطرف الثالث: شخص طبيعى أو اعتبارى عام أو خاص، خلاف المعلف طالب المعلومة والمؤسسة المقدم لها الطلب.

الإخطار : يقصد به إبلاغ الطالب برد الموظف المختص ويكون

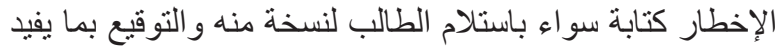
ذللك أو بكتاب مسجل بعلم الوصول على عنو الطان الطالب.

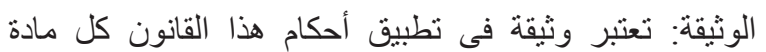

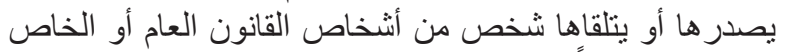

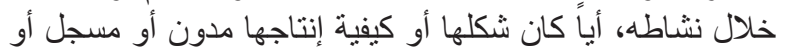

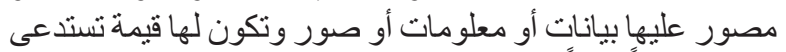
حفظها حفظاً دائماً.

الوثيقة العامة: كل مادة بصدر ها أو يتلقاها شخص من أشناص

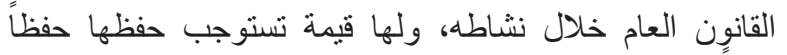
دائماً.

الوثيقة الخاصة: كل مادة يصدر ها أو يتلقاها شخص من أشخاصِ القانون الخاص خلال نشاطه، ولها قيمة تستوجب حفظها دائماً.

مدة الإتاحة: المدة التى بانقضائها تصبح الوثائق الجارية أو الأرشيفية متاحة للكافة. الدار: دار الوثائق القومية بالهيئة العامة لدار الكتب و الوثائق

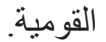

مدة الحفظ: المدة التى تحفظ خلالها الوثائق فى جهة إنشائها قبل نقلها إلى الأرشيف الوسيط أو إلى الدار أو بها.

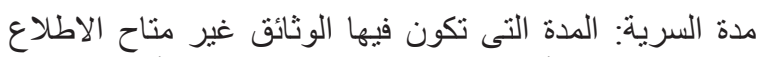

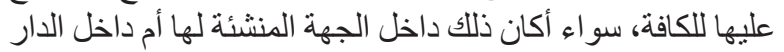

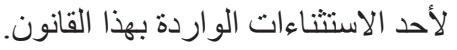

الأرشيف الجارى: هو كل الوثائق المستخدمة باستمرار من

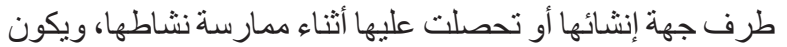
حفظها بالجهة التى أنثأتها أو تلقتها أثناء ممار ستها لنشاء لنشاطها. الأرشيف الوسيط: الوثائق التى انتهى استخدامها كأرشيف جار بار التهاء

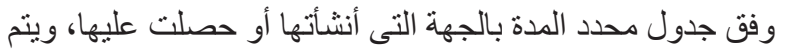
حفظها بالدار.

الأرشيف الدائم (التاريخى): الوثائق التى انتهت فترة حفظها فى الونى

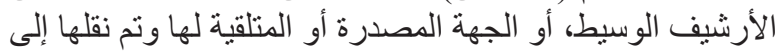

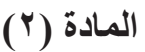

يهدف هذا القانون إلى: - الى 1 ـ تمكين المو اطن و المقيم بصورة شر عية فى مصر من ممارسة
حول سوء التصرف، أي حماية المسئولية لكل موظف يقوم بنية

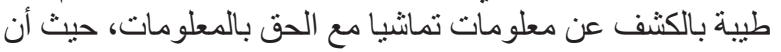

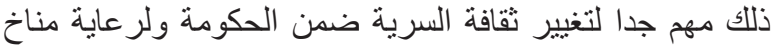

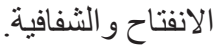

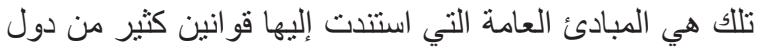

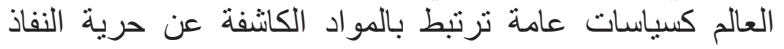

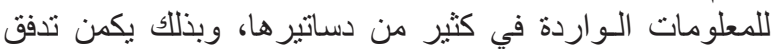

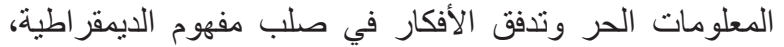
و هو أساس لإبداء احترام فعلي لحقوق الإنسان، كما يعتبر مبدأ

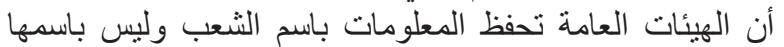

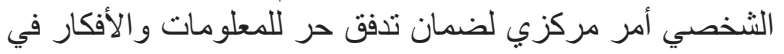
الممارسة الفعلية للمو اطنين.

وقد نصت المسودة الأولية لمشروع قانون حرية المعلومات

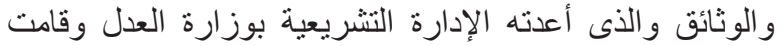

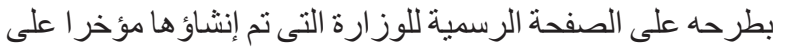

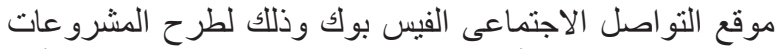

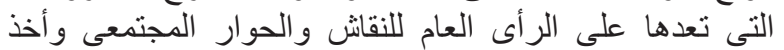
وجهات النظر المختلفة لتعديله.

ويتضمن قانون حرية المعلومات و الوثائق إنشاء مجلس أعلى إنى إنى

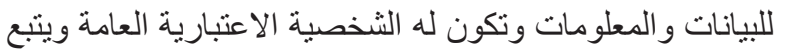

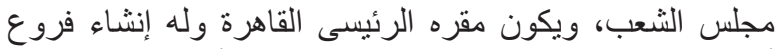

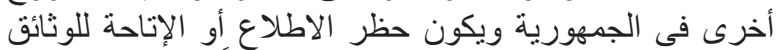

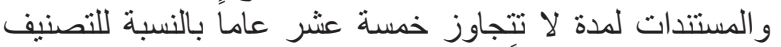

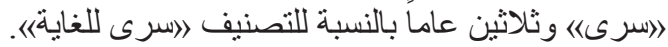

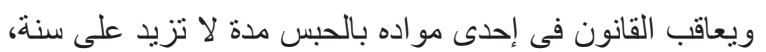

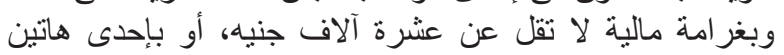

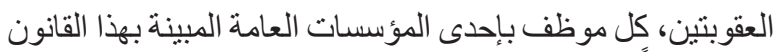
حجب عمدا معلومات جائز الاطلاع عليها.

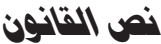

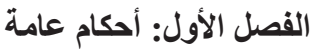

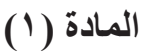

... فى تطبيق أحكام هذا القانون يقصد بالمصطلحات التالية

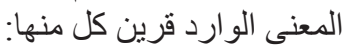
المجلس: المجلس الأعلى للبيانات و المعلومات.

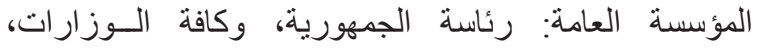

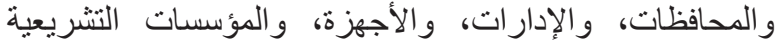
و القضائية و التنفيذية، و الهيئات المحلية، و المؤسسات الخاتية الخاصة التى

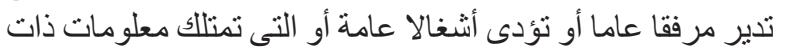

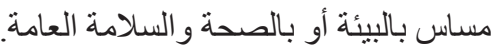

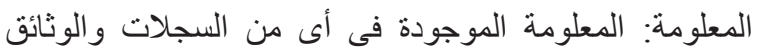

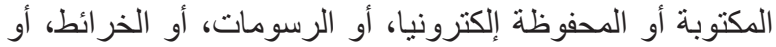

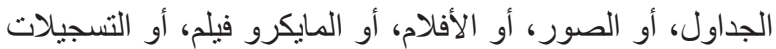

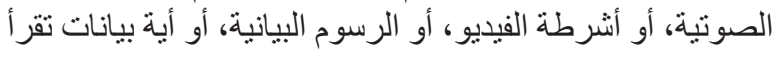


بأهمية حق الاطلاع وتمكين المواطن من ممارسته، وكيفية حفظ

المادة ( • (1)

يجب على المؤسسات العامة نشر تقارير سنوية تتضمن على

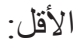

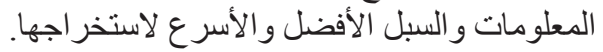

حق الحصول على المعلومات الموجودة لاى المؤسسات العامة

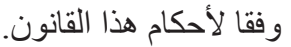
r ب. بث روح الثفافية والمساءلة فى المؤسسات العامة وتشجيع

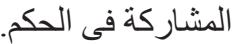

المادة (r) المناركة (ب)

تلنزم كافة المؤسسات العامة بإنشاء موقع لها على شبكة المعلومات

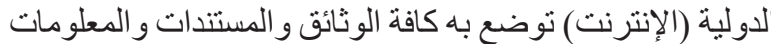
المتاحة للعامة التى تصدر ها أو تتلقاها.

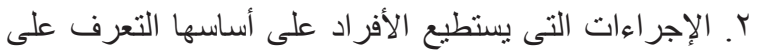

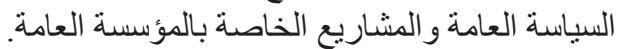

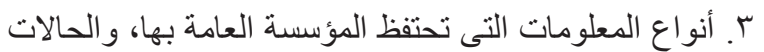
التى تحفظ بها. ع. مضدون القرارات الهامة التى تصدر ها، وأسباب اتخاذها

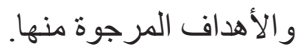
ه. أية معلومات أخرى ترى إدارة المؤسسة ضرورة مهرة نشر ها.

المادة (1) (11)

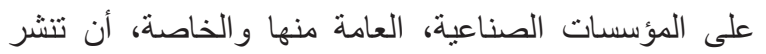
تقارير نصف سنوية تبين بها على الأقل المعلومات الآتية:

1. مناطق حفظ المو اد السامة المستعملة وطبيعتها ومخاطر ها. r كمية الانبعانات الصادرة عن التصنيع. r. كيفية التخلص من النفايات. الفصل الثانى: المجلس الأعلى للبيانات وللمعلومات

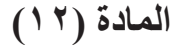

ينشأ المجلس الأعلى للمعلومات و البيانات، وتكون له الثخصية

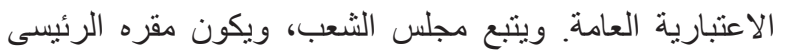

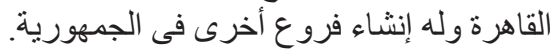

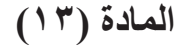

يهذف المجلس إلى ضمان تطبيق أحكام هذا القانون، وتحقيق

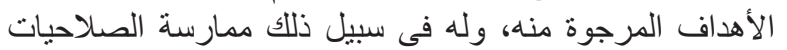

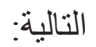

1 - وضع وتنظيم وتنفيذ البر امج والخطط و السياسات الخاصة

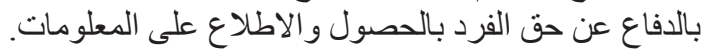

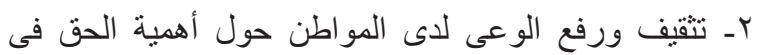
الاطلاع و النتائج الإيجابية لممارسته على لـى صعيد الفرد و المجتمع الهئ

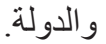
rـ المساهمة في تدريب الموظفين و المسئولين فى المؤسسات

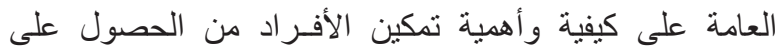

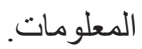
ع - رصد المخالفات ونشر التقارير و الدراسات التى تتضمن معوقات ممارسة الحق فى الاطلاع وكيفية التظلب عليها.

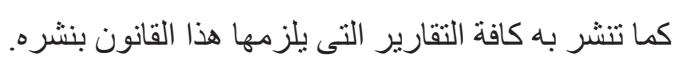

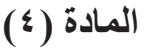

تصنف جميع المعلومات التى بحوزة كافة المؤسسات العامة

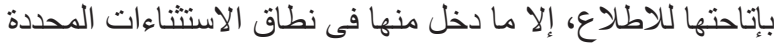

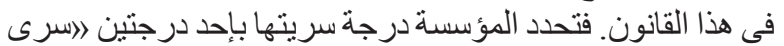
أو سرى للغاية)ا.

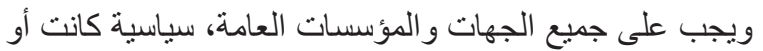

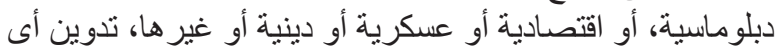

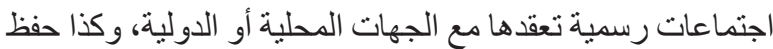
أية معلومات أو بيانات أو وثائق تصدر ها أو تثتلقاها.

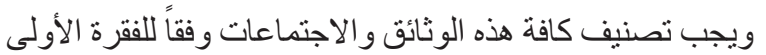

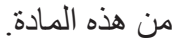

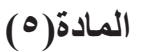

يكون حظر الاطلاع أِو الإتاحة للاثنائق والمستندات لمدة لاِ

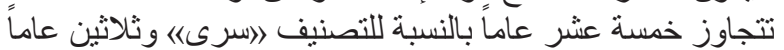
بالنسبة للتصنيف 》إنرى للغاية|).

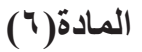

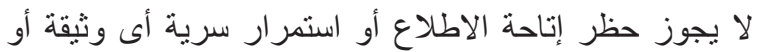

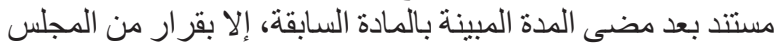

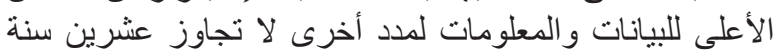

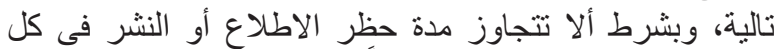

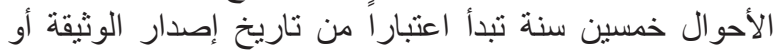
المستتد أو تلقى المؤسسة لها.

(V) المادة (v)

يجب على كل مؤسسة عامة أن تكلف موظفا أو أكثر يختص بالنظر فى طلبات الحصول على المعلى المعلومات، ويمنح الصلاحيات اللازمة للبحث و الوصول إلى المعلومة المطلوبة.

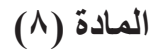

على المؤسسات العامة أن تحتفظ بالمعلومات التى بحوزتها بشكل منظم وبترتيب يسهل على الموظف المختص عملية استخر اجها، وتر اعى كافة المؤسسات العامة حفظ المعلومات إلكترونيا كلما

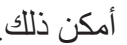

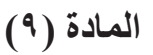

على المؤسسات العامة تنظيم دورات تدريبية لموظفيها تتعلق 


$$
\text { ع - إقرار الموازنة السنوية للمجلس. }
$$

0ـ وضع القواعد العامة التى يتعين على المؤسسات العامة اتباعها لإتاحة المعلومات.

7ـ نظر التظلمات المقدمة من ذوى الثأن ضد المؤسسات العامة عن مخالفة الأحكام التنظيمية لهذا القانون.

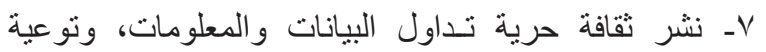

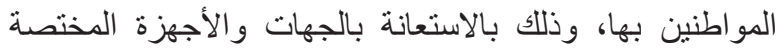
بشئون التعليم، و التنشئة، و الإعلام و التنقيف. بالنيف

^ــ عقد المؤتمرات و الندوات و وإجـراء الأبحاث و والتدريبات

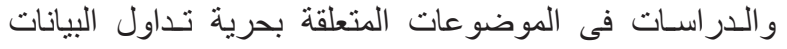

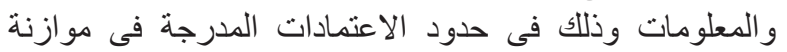

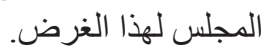

9 - إصدار التقارير و النشر ات و المجلات و المطبو عات المتصلة

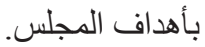

• ـ ـ تقديم المقترحات اللازمة لدعم القدر ات المؤسسية و الفنية فى

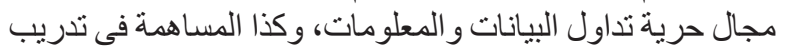

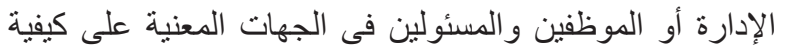
و أهمية تمكين الأفر اد من الحصول ولعن على المعلومات.

1 ا ـ التعاون مع المنظمات و الجهات الوطنية و الإقليمية و الدولية

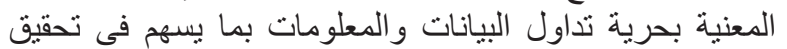
أهداف المجلس وتنمية علاقته بها. r ا ـ قبول الهبات و التبر عات و الإعانات و المنح.

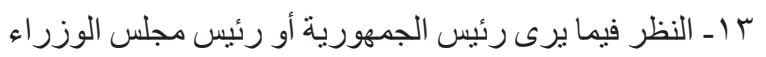

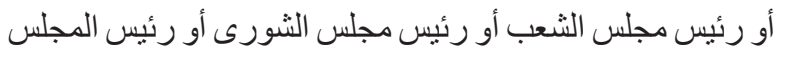
عرضه على المجلس.

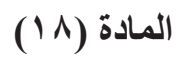

يتمتع المجلس بالصلاحيات التالية:

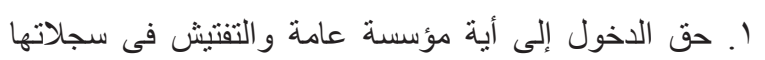

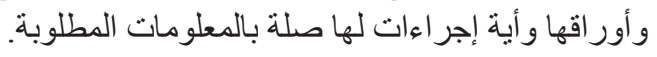

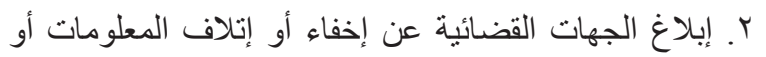
تعديلها بشكل مخالف لحقبقتها بقصد التهرب من تقديمها.

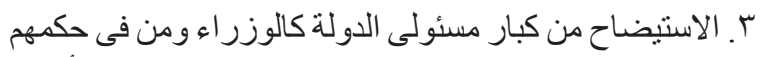

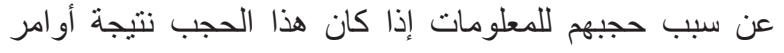
صادرة عنهم مباشرة.

المادة (9) (19)

تتكون موارد المجلس مما يلى:

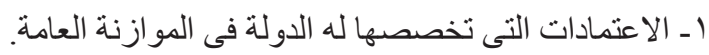

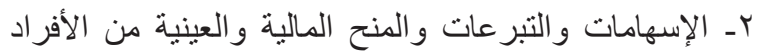
و الهيئات المحلية أو الأجنبية التى يقبلها الماتح المجلس.

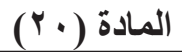

المادة (ع 1 )

يصدر بتشكيل المجلس قرار من رئيس الجمهورية على النحو

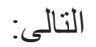

1 ـ ثلاثة أعضاء يختار هم رئيس الجمهورية.

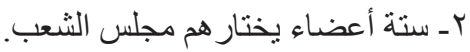

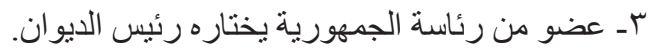
عـ عضو من وزارة الخارجية يختاره الوزير. هـ عضو من هيئة الأمن القومى يختاره رئيسها.

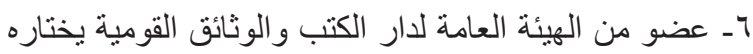

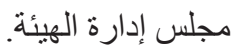
V- عضو من جهاز الإحصاء والتعبئة العامة يختاره رئيس

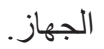

^ـ عضو من المجلس القومى لحقوق الإنسان يختاره رئيسه.

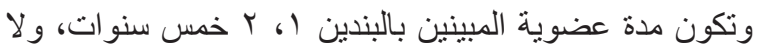

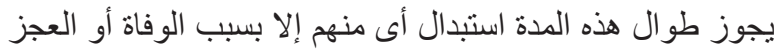
أو الاستقالة أو الحكم عليه بعقو بة مقيدة الئة للحرية.

المادة (10)

يختار المجلس فى أول اجنماع له رئيساً من بين الأعضاء المبينين بالبندين 1، ب من المادة السابقة.

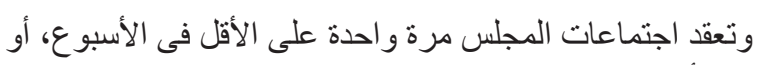

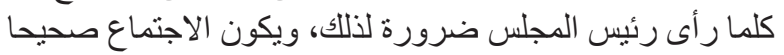

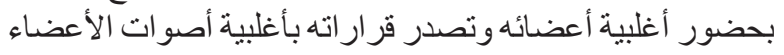
الحاضرين، و عند التساوى يرجح الجانب الذئى منه الرئيس.

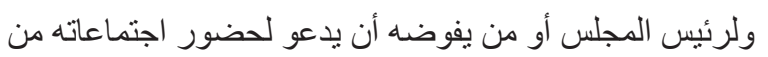

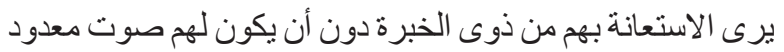

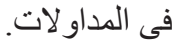

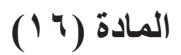

يتفر غرئيس المجلس و الأعضاء طو ال فترة عضو يتهم بالمجلس، و لا يجوز لأيهم أن يشغل أى منصب أل أو وظيفة سو اء بأجر أو أو بدون أجر طوال فترة العضوية.

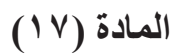

للمجلس فى سبيل تحقيق أهدافه أن يباشر جميع التصرفات و الأعمال اللازمة لذلك، دون التقيد بالقو اعد و النظم الحكومية. وله له

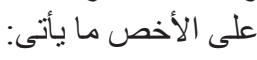
1 - وضع الهيكل التنظيمى و الإدارى للمجلس.

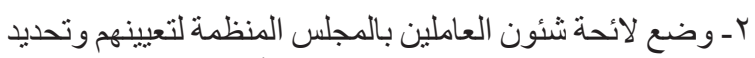

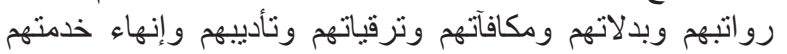

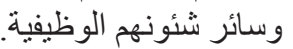
بـ- وضع اللوائح الداخلية المتعلقة بالثئون الفنية والمالية

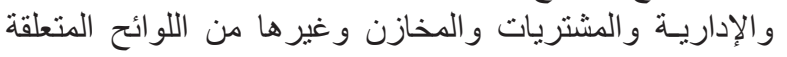
بتنظيم نشاط المجلس. 


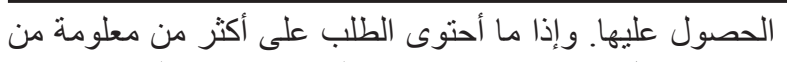

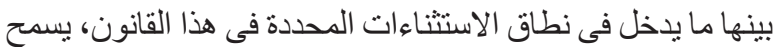
للطالب بالاطلاع على الجزء المناء الماح فقط من المعلومات.

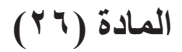

يجب على الموظف المختص عند الموافقة على الطلب أن يقدم

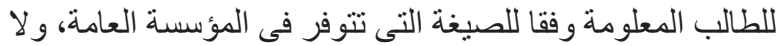
يجوز للموظف أن يكتفى باطلاع الطالب عليها شفاهة. للإنة وتحدد اللائحة التنفيذية نوع الصيغ وكيفية حصول الطالب عليها.

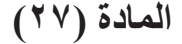

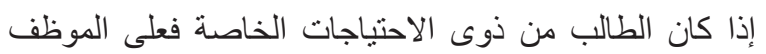

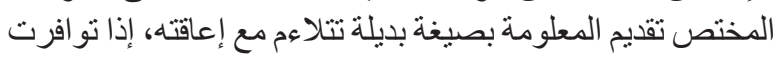
هذه الصيغة فى المؤسسة.

المادة (Y^)

يجوز للموظف المختص إحالة الطلب لمؤسسة أخرى - و إخطار

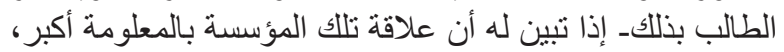

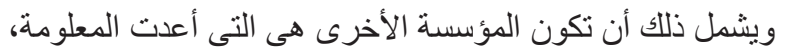
أو أنها تمنلك صيغا بديلة لها نهون.

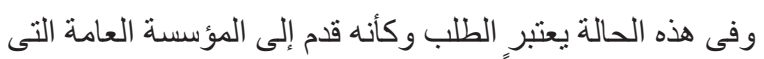
أحيل لها الطلب اعتباراً من تاريخ الإحالة إليها.

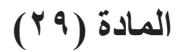

لا يجوز رفض أى طلب للإفصاح عن معلومة إلا لأحد السببين الآتيين:

\section{1. أن المعلومة ليست بحوزة المؤسسة.}

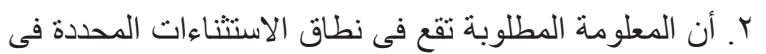

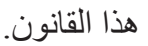
الفصل الر ابع: الاستثناءات

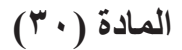

على الموظف المختص رفض الكثف عن أية معلومة إذا كانت

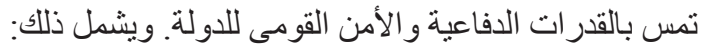

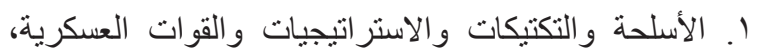
و العمليات العسكرية التى تهدف إلى حماية الوطن.

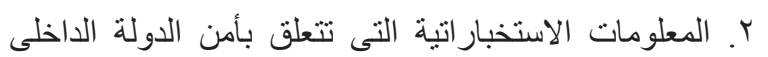
و الخارجى وفقا للقو انين النافذة.

r. الاتصالات و المر اسلات الدولية ذات الصلة بالشئون الدفاعية و التحالفات العسكرية.

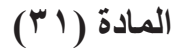

على الموظف المختص رفض الكثف عن أية معلومة تخص دولة أو منظمة أجنبية تم الاتفاق معها على إبقاء هذه

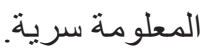

يلتزم المجلس بتقديم تقارير دورية كل ستة أشهر إلى كل من رئيس

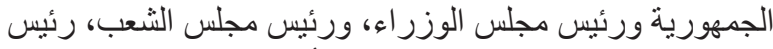
المجلس القومى لحقوق الإنسان. ويجب أن تحتوى التقارير على على

$$
\begin{aligned}
& \text { ا ـ حالات الامتناع غير المبررة عن تقديم المعلومات. } \\
& \text { r. المعوقات التى نو اجهه في تتفيذ مهامه. } \\
& \text { r. أية توصيات أخرى يرى المجلس أهميتها. } \\
& \text { الفصل الثالث: إجر اءات طلب الحصول على المعلومات }
\end{aligned}
$$

المادة (Yl)

تحدد كل مؤسسة عامة الرسوم على طلبات الحصول على العي

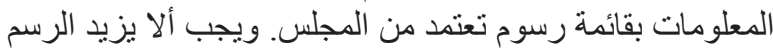
فى كل الأحو ال عن ضعف رنف كلفة استخر اجها.

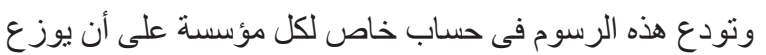

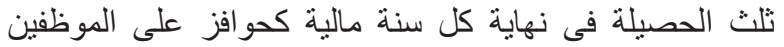

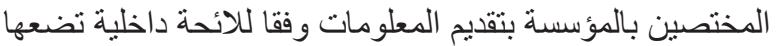

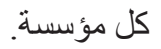
و وتلتزم كل مؤسسة بالإعلان عن هذه القائمة بمقر تقديم طلبات

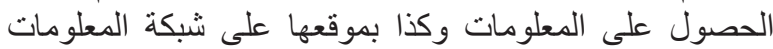

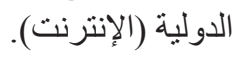

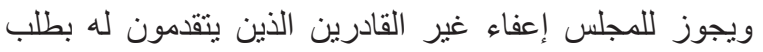

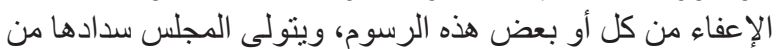

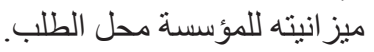

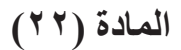
يقدم طلب الحصول على المعلومات إلى المؤسسة التى تحتفظ بها،

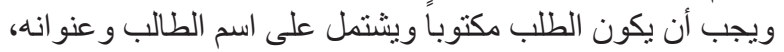

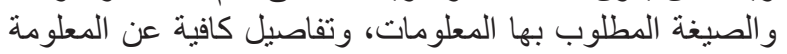
المطلوبة تمكن الموظف المختص من استخر اجها بجهـ بسيط.

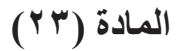

على الموظف المختص فور تسلمه الطلب أن يقيده بسجل خاص،

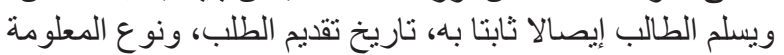

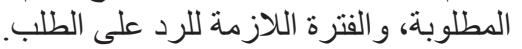

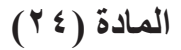

على الموظف المختص إخطار الطالب بالرد على الطلب خلال

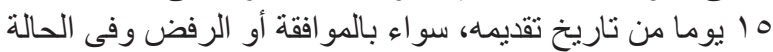

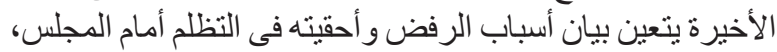

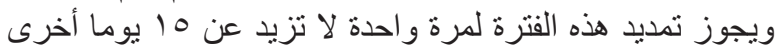

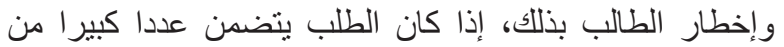

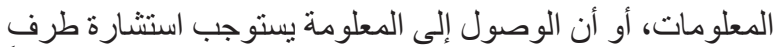

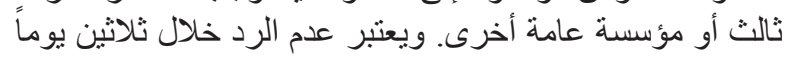
بمثابة رفض للطنا

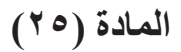
إذا تمت الموافقة على الطلب فعلى الموظف المختص أن أن يمكن

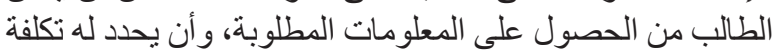




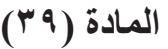

يجب على كافة المؤسسات العامة والخاصة رفض الكثف عن أية بيانات أو معلو مات تخص طر فا ثالثا وتتعلق بحياته الخاصة إلا الا

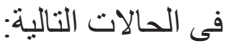
ا ـ إذا و افق الشخص صاحب العلاقة كتابة على هذا الكثف. r. إذا كانت هذه المعلومة منشورة بشكل علنى. ". إذا طلب هذا الكثف بموجب أمر أو حكم قضائى أو موافقة

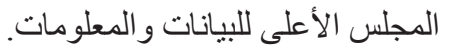
ع. إذا كان مقدم الطلب وصيا على الطرف الثالث. ه. إذا كان مقدم الطلب من أقارب الطرف الثالث حتى الدرجة

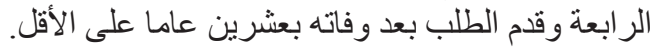

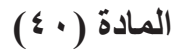
لا يجوز توقيع أية عقوبة على الموظف الذى بفشى بمعلومات تتعلق بكثف للفساد أو بمخالفات البيئة أو انتهونئ لاكات حقوق الإنسان.

$$
\text { الفصل الخامس: إجر اءات التظلم و الطعن }
$$

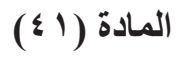

يجوز التظلم للمجلس الأعلى للبيانات و المعلومات فى الحالات الآتية:

$$
\text { ا ـ رفض المؤسسة الطلب بالحصول على المعلومات. }
$$

Y. فرض رسوم على الطلب تتجاوز القيمة المحدة بالقائمة المعتمدة من المجلس.

r. رفض الطلب بالحصول على المعلومة بصيغة بديلة. ع. تجاوز الفترة الزمنية اللازمة للإجابة على الطلب المبينة

$$
\text { بالمادة (ع Y ) من هذا القانون. }
$$

○ـ إحالة الطلب إلى أكثر من مؤسسة دون الموافقة عليه.

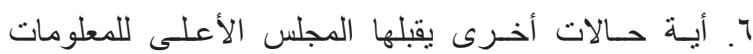

$$
\text { و البيانات. }
$$

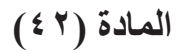

ميعاد التظلم ثلاثون يوماً تبدأ من تاريخ الإخطار بالإجراء موضوع التظلم.

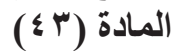

يقدم التظلم إلىى المجلس - بغير رسوم- بصحيفة موقعة من المتظلم

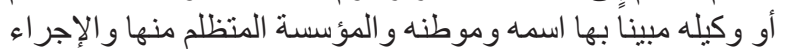
محل التظلم.

ويقيد التظلم بسجل خاص ويسلم المتظلم ما يفيد تاريخ تقديمه.

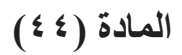

يجب على المجلس فور استلام التظلم إرسال صورة منه للمؤسسة

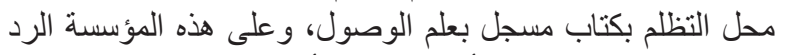
على التظلم للمجلس خلال أسبوع على الأكثر من تاريخ استلامها له له.

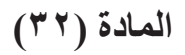

لا يجوز للموظف المختص رفض الكثف عن المعلومات، فى المي

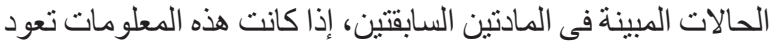

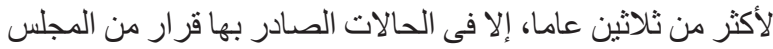

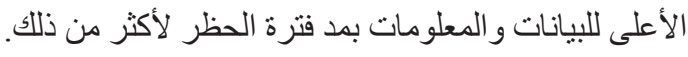

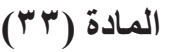

يحق للموظف المختص فى المؤسسات التى تتولى مهمة التحقيق

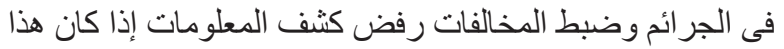

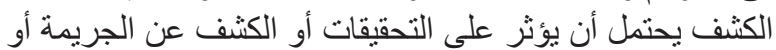

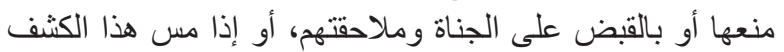

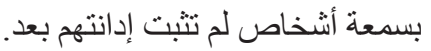

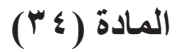

يجوز للموظف المختص رفض كثف أى معلومة تحتوى على:

$$
\text { ا ـ أسرار مهنية أو تجارية تخص المؤسسة. }
$$

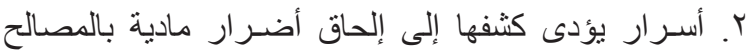

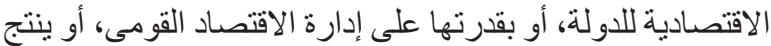

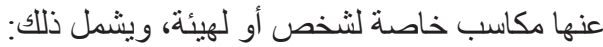

أ. التغييرات المتوقعة فى أسعار العملة المتداولة فى جمهورية

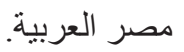

ب. التغييرات المتوقعة فى رسوم التعريفة الجمركية و الضر ائب و الرسوم وأية مصادر أخرى للإير ادات.

ج. التغييرات المتوقعة فى أسعار الفائدة المتعلقة بالقروض

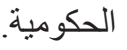
د. التغييرات المتوقعة فى أسعار الممتلكات الحكومية من أسهم و أمو ال منقولة و عقار ات.

هـ. أية صفقات مستقبلية تنوى المؤسسة العامة عقدها.

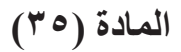

يجب على الموظف المختص رفض الكثف عن أى معلومة

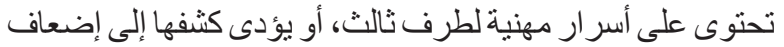
الوضع التنافسى لهذا الطرف، إلا بمو افقة كتابية من الأخير بذلك.

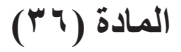

يجوز للموظف المختص رفض كثف المعلومة إذا كانت تتعلق

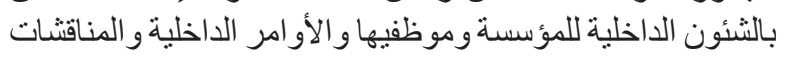
و المقترحات الأولية.

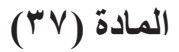

يجوز للموظف المختص رفض كثف المعلومة إذا كانت ثتعلق بتوقعات غير مؤكدة عن كوارث طبيعية أو أمر اض معدية.

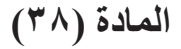

يجوز للموظف المختص رفض الكثف عن أية معلومة يمكن أن يؤدى كثفها إلى المساس أو إلحاق الضرر بسلامة الأفر الفر اد. 
الاطلاع عليها و الحصول على نسخ منها وفقاً للإجر اءات

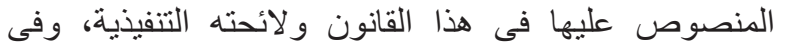
حدود قائمة الرسوم المعتمدة من المجلس الأعلى للبيانات و المعلومات.

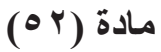

يجوز للادار - دون التقيد بأحكام قانون المناقصات و المز ايدات

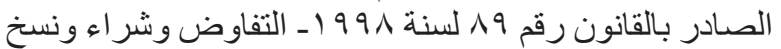

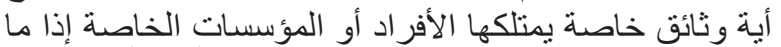
رأت اللجنة الفنية بها أهمية حفظها بالدار حفظاً دائماً.

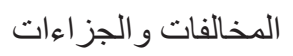

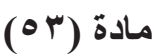

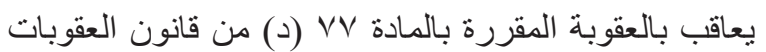

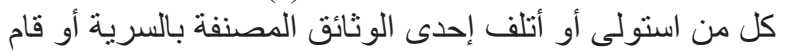
بفض حرز ها طو ال فترة حظر ها.

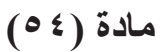

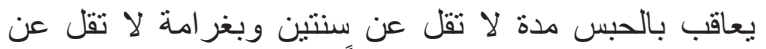
خمسين ألف جنيه كل من أتلف عمداً سجلا أو وثثيقة عامة لإحدى لإنى

المؤسسات العامة أو المودعة دار الكتب و الوثائق القومية. وتضاعف العقوبة إذا ارتكبت الجريمة من أحد الموظفين المختصين بحفظ المستندات أو الوثائق أو تداولهات

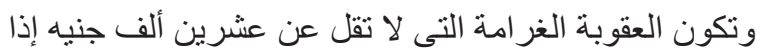

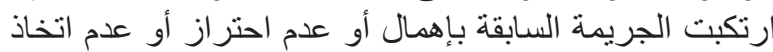
الاحتياطات الو اجبة للحفاظ على المستند أو الوثيقة.

مادة (00)

يعاقب بالحبس مدة لا تقل عن سنة و بغر امة لا تقل عن عشئ عنرة آلاف جنيه أو بإحدى هاتين العقوبتين كل من قدم للغين لإنير دون

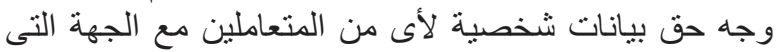
يعمل بها سو اء كانت عامة أو خاصة.

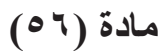

يعاقب بالحبس مدة لا تزيد عن سنة، وبغر امة مالية لا تقل عن عشرة آلاف جنيه، أو بإحدى هاتين العقوبتين، كل موظف

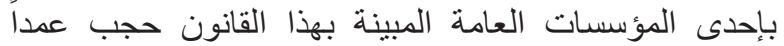

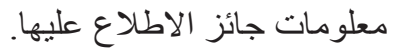

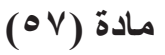

يعاقب بالحبس مدة لا تقل عن ثلاثة أثشهر و لا نزيد عن سنة

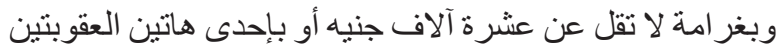

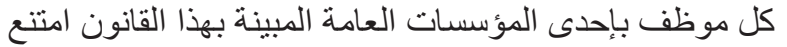
عن تنفيذ قرار المجلس الأعلى للبيانات و المعلومات المبنة

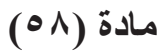
يعاقب بذات العقوبة المنصوص عليها فى المادة السابقة كل من أعطى بسوء نية معلومات مغلوطة بغرض تضلية الطيل مقدم
المادة (0)

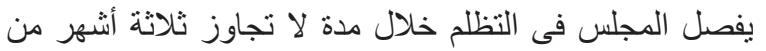

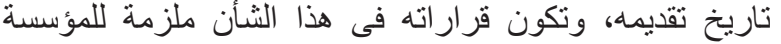

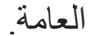

المادة (7 (

يجوز الطعن على قرار ات المجلس أمام القضاء الإدارى، وينظر الطعن بذات إجر اءات نظر الطلبات المستعجلة. الفصل السادس: حفظ الوثائق

مادة ( ) (

تلنزم كافة المؤسسات بحفظ جميع الوثائق والمستندات التى التى

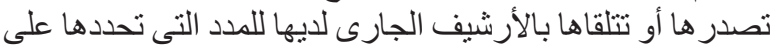

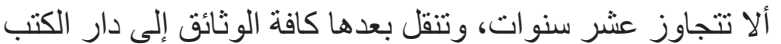
و الوثائق القومية.

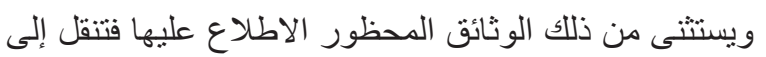

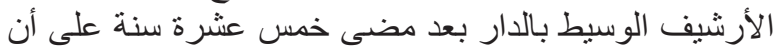

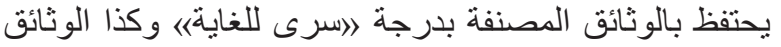

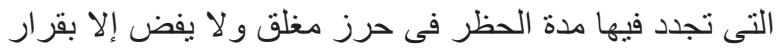

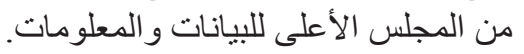

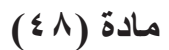
تؤول إلى الدار الوثائق الآتية:

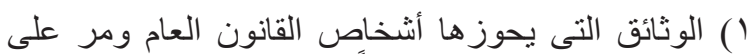

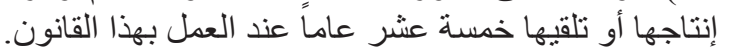

r) الوثائق العامة التى تحوز ها أى جهة تنقضى شخصيتها القانونية لأى سبب من الأسباب.

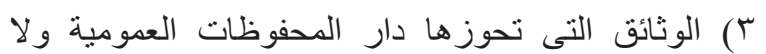

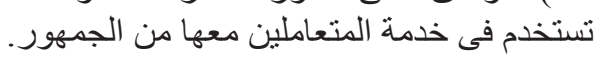

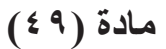

تشكل بالدار لجنة أو أكثر من الخبراء الفنيين تكون مهمتها

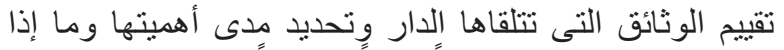
كانت تستدعى حفظها حفظاً مؤقتاً أو دائماً من عدمه.

وتحدد اللائحة التنفيذية إجر اءات تشكيل هذه اللجنة وطريقة

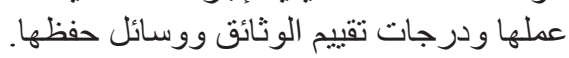

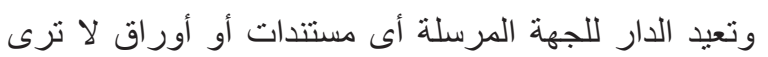
اللجنة المشار إليها أنها ذات قيمة تستدعى حفظها.

مادة (••)

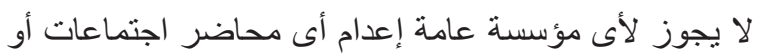

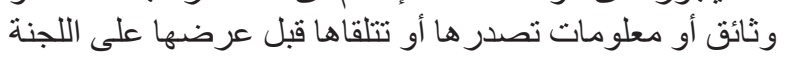
المشار إليها بالمادة السابقة.

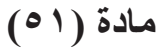
تحتفظ الدار بكافة الوثائق المتاحة وكذا التى انتهى فترة حظر الاطلاع عليها بالأرشيف الدائم (التاريخى) وكنى وتكفل للكافة 